\title{
EFEITO DO EXTRATO DE LARANJA AMARGA (Citrus aurantium) EM ROEDORES OBESOS
}

(Effect of bitter orange extract (Citrus aurantium) on obese rodents)

${ }^{1}$ Feliphe Boaventura, ${ }^{2}$ Carolina Grassi Warnecke, ${ }^{2}$ Thais Andrade Costa Casagrande

${ }^{1}$ Universidade Federal do Paraná, Curitiba, Paraná, Brasil. ²Universidade Positivo, Curitiba, Paraná, Brasil.

*Correspondência: felventura@yahoo.com.br

RESUMO: A obesidade é uma doença presente na sociedade a qual os indivíduos acometidos possuem alterações cardiovasculares e metabólicas que causam efeitos negativos na qualidade de vida e contribuem na evolução de enfermidades. Sendo assim o controle do peso é associado a manutenção da saúde. Neste contexto, há muitas alternativas para alcançar a redução e o controle de peso, uma delas é a utilização de fitoterápicos, como uso da Citrus aurantium sbsp (laranja amarga). A laranja amarga promove aceleração metabólica por meio do seu efeito termo gênico auxiliando na perda e no controle de peso, no entanto, os efeitos adversos desencadeados pelo uso deste fitoterápico não é bem elucidado pela literatura. Afim de compreender os possíveis efeitos adversos causados do uso de laranja amarga no tratamento da obesidade. O presente trabalho foi aprovado pelo comitê de ética animal (CEUA), da Universidade Positivo com o protocolo de aprovação 507-19, e realizado nas dependências da Universidade Positivo, Curitiba, Paraná, no setor Biotério laboratório de criação e experimentação anila. Para isto foram utilizados 50 ratos machos da linhagem Wistar, estes animais foram submetidos a um protocolo dietético de indução de obesidade e diabetes no período de 120 dias, após término deste período, os animais foram agrupados em 5 grupos distintos, cada grupo era composto por 10 unidades experimentais. O grupo controle negativo onde foi administrado apenas água deionizada, controle positivo onde os animais receberam efedrina e os demais grupos receberam 3 diferentes concentrações de Citrus Aurantium sbsp 100, 300 e $1000 \mathrm{mg} / \mathrm{kg} / \mathrm{dia}$ pelo período de 8 semanas. Ao término do experimento foi observado que não houve diferença significativa em relação saciedade e a ação emagrecedora do extrato de laranja amarga nas concentrações testadas, no entanto houve variação no ganho de peso médio dos animais, em comparação com o grupo controle, os demais grupos obtiveram menor ganho peso durante o período de tratamento. Em relação aos efeitos hepáticos houve diferença significativa em todos os grupos testados com intervalo de confiança de $5 \%$, sendo a concentração $1000 \mathrm{mg} / \mathrm{kg} / \mathrm{dia}$, a concentração que maior promoveu efeito hepatoprotetor, os níveis de triaglicerídeos e colesterol também foram menores nos grupos testes e controle positivo quando comparados com grupo controle negativo. Em relação aos efeitos comportamentais, animais tratados com extrato de laranja amarga demonstraram comportamentos atípicos relacionados a desconforto e dor abdominal.

Palavras-chave: comportamento; diabetes mielites; fitoterápico; ganho de peso; hepatoprotetor.

\section{Agradecimentos}

Agradecemos primeiramente aos animais, por doarem suas vidas em prol do desenvolvimento científico e acadêmico. Aos técnicos da Universidade Positivo que sempre foram solícitos e contribuíram em todas as etapas do projeto e por fim aos metres e Doutores do Curso de Medicina Veterinária da instituição por nos encorajar e dar subsídios técnicos para realização deste trabalho. 